\title{
Venomous Snakebites in Canada: A National Review of Patient Epidemiology and Antivenom Usage
}

\author{
Gwynn Curran-Sills, MD, MMedSc; Jenna Kroeker, BSc \\ From the Department of Family Medicine, University of Calgary, Calgary, Canada (Dr Curran-Sills); the 15 Field Ambulance, Calgary \\ Detachment, Canadian Armed Forces, Calgary, Canada (Dr Curran-Sills); and the Northumbria University, Newcastle-upon-Tyne, United \\ Kingdom (Ms Kroeker).
}

\begin{abstract}
Introduction - There are 3 pit viper species in Canada. Limited Canadian literature exists on the epidemiology of venomous snakebites and the treatment patterns with antivenom. This study described the epidemiology, the utilization of antivenom, and estimated expenditures due to forfeited antivenom for pit viper envenomations in Canada.

Methods-A retrospective review of the Health Canada Special Access Program records to generate descriptive statistics. Data are presented as mean \pm SD (range), as appropriate.

Results-The geographic distribution of Canadian pit viper species is presented. There were 99 envenomations reported in Canada from January 2009 to December 2015. The number of envenomations per year was $14 \pm 6(6-21)$. CroFab and Antivipmyn are used in Canada to treat envenomations. The number of vials for patient treatment was $17 \pm 12$ (3-66) and 16 \pm 9 (6-42) for CroFab and Antivipmyn, respectively. Antivenom stock usage for patient treatment varied across the country with provincial means reported for British Columbia (33\%), Alberta (37\%), Saskatchewan (27\%), and Ontario (71\%). The costs incurred secondary to forfeited stock where estimated as: \$1,280,000 USD in British Columbia, \$255,000 in Alberta, \$60,000 in Saskatchewan, and \$0 in Ontario.

Conclusions-The absolute number of annual envenomations is small and the 3 Crotalinae species are limited to relatively narrow geographic areas in British Columbia, Alberta, Saskatchewan, and Ontario. The utilization of antivenom in the treatment of patients revealed that regions where the western and prairie rattlesnake reside forfeited a substantial amount of antivenom from 2009 to 2015. Organizations responsible for maintaining antivenom supplies on a provincial or regional level could use these data to guide antidote stocking and reduce costs.
\end{abstract}

Keywords: pit viper, envenomation, cost analysis, health resources

\section{Introduction}

Canada has diverse fauna spread over a large geographic area but fortunately has few venomous species. Specifically, in the case of snakes, there are 3 endemic venomous snake species in Canada that fall within the pit viper (Crotalinae) taxonomic subfamily and include the western rattlesnake (Crotalus oreganus), the prairie rattlesnake (Crotalus viridis), and the eastern massasauga rattlesnake (Sistrurus catenatus). Previously, the timber rattlesnake (Crotalus horridus) was also found in

Corresponding author: Gwynn Curran-Sills, 417 - 15 ST NW, Calgary, AB, Canada; e-mail: gwynn.curran.sills@utoronto.ca.

Submitted for publication October 2017.

Accepted for publication June 2018.
Ontario but was eradicated consciously by people in the 19th century. ${ }^{1}$ These remaining species are found in many parts of North America, and much of our understanding of the epidemiology and treatment comes from experience in the United States. ${ }^{2-5}$ A single publication through the government of British Columbia reports 3 to 4 envenomations per year for the western rattlesnake, with a single fatality among 63 bites in this jurisdiction. ${ }^{6}$ Beyond this limited characterization of the frequency of envenomation for one of these pit viper species, there is no identified literature that describes the epidemiology or treatment of patients bitten by venomous snakes in Canada.

Health Canada has not granted approval for CroFab Crotalidae Polyvalent Immune Fab (Ovine) (BTG International Inc, West Conshohocken, PA) or Antivipmyn 
Polyvalent Equine Anti-viper Serum (Instituto Bioclon, S.A. de C.V., Mexico City, Mexico) in the treatment of Crotalinae envenomations. The Health Canada Special Access Program (HCSAP) allows healthcare professionals to access treatments not approved or currently marketed in Canada for life-threatening conditions or emergencies if there is evidence of its efficacy or if this treatment has received approval in another jurisdiction. Since 2009 the HCSAP has acted as the conduit through which healthcare facilities and private organizations in Canada can obtain snake antivenom. To access this program, a special access request form A must be completed before the antivenom can be released to the requesting organization from the manufacturer. These forms can be completed for anticipated future use or to replenish stock used in the direct treatment of a patient.

Understanding the epidemiology of snake envenomations and the antivenoms used in Canada at the regional and provincial level can guide treatment practice and antivenom stock requirements. The study objectives were twofold: 1) to review the geographic distributions of pit viper species in Canada, and 2) to use the HCSAP documentation to identify the epidemiology of pit viper envenomations and trends in the utilization of antivenom in Canada and estimate expenditures due to forfeited antivenom.

\section{Methods}

Ethics approval for this project was obtained through the University of Calgary (REB13-0815).

HCSAP documents (HCSAP request form A) related to antivenom requests from January 2008 to April 2016 were obtained through the Access to Information Program of Health Canada. These documents were redacted of personal identifiers and contained the following fields of interest: the location of the facility where treatment occurred or future use was expected (province and city), date of request for medication, medication requested, manufacturer, number of vials requested, number of vials released, indication for the medication, patient's year of birth, patient's sex, date administered, and the number of vials used for treatment or for future use. These fields were translated into a Microsoft Excel database by one investigator (JK) who was not blinded to the study objectives. Duplicate records were removed and patients who received multiple doses of antivenom over several days (maximum $7 \mathrm{~d}$ ) were combined into a single entry. Descriptive statistics were generated and, where possible, means and standard deviations were calculated, along with the range. Rounding to whole numbers was undertaken for all calculated means. These calculations and a graph were constructed using Microsoft Excel.
Maps were created to illustrate the endemic distributions of pit viper species in Canada and were a composition of the available herpetology data from provincial, ${ }^{6-9}$ federal, ${ }^{10-12}$ and international ${ }^{13,14}$ sources. More recent sources were given greater weight when determining boundaries. Natural Resources Canada provides open access online geographic information systems software ${ }^{15}$ that allowed for the generation of regional endemic maps.

To correlate the HCSAP data to a specific snake species, this study made the following assumptions: 1) the treating clinician believed the patient was bitten by a Crotalinae species, 2) the snakebite was the result of 1 of 3 Crotalinae species in Canada, and 3) the determination of the Crotalinae species is based upon the endemic distribution of the snake species in relation to the location of the treatment site.

Antivenom stock usage is defined as the total number of vials used per treatment divided by the total number of vials requested multiplied by 100 . Forfeited antivenom was defined as antivenom that expired while in the organization's possession, was wasted during administration, or was given to another jurisdiction without cost. The cost secondary to forfeited stock for each of the 3 pit viper species was extrapolated by multiplying the cost per vial by the number of forfeited vials. The number of forfeited vials equaled the total number of vials accessed through HC from 2009 to 2015 minus the total number of vials accessed through $\mathrm{HC}$ from 2013 to 2015 (to account for the 3 years of unexpired antivenom) minus the total number of vials used for treatment from 2009 to 2015. The manufacturers of CroFab and Antivipmyn indicated that users of the HCSAP could purchase these products for $\$ 2500$ and $\$ 750$ USD per vial, respectively (September 2017). The manufacturers also stated that the shelf life for each product is $3 \mathrm{y}$. The author conducted personal telephone interviews (September 2017) with the pharmacy managers in Oliver, British Columbia (T. Macleod), southern Alberta (M. Wisnowski), and Parry Sound, Ontario (N. Bruneau). These individuals were responsible for hospital or regional purchasing of either CroFab or Antivipmyn and indicated that their respective organizations purchased these products at full retail costs. No wholesale, negotiated, or bulk pricing was obtained.

\section{Results}

The potential endemic distribution of the western rattlesnake, the prairie rattlesnake, and the eastern massasauga rattlesnake species in British Columbia, the prairies including Alberta and Saskatchewan, and Ontario, is outlined in Figure 1. 
A
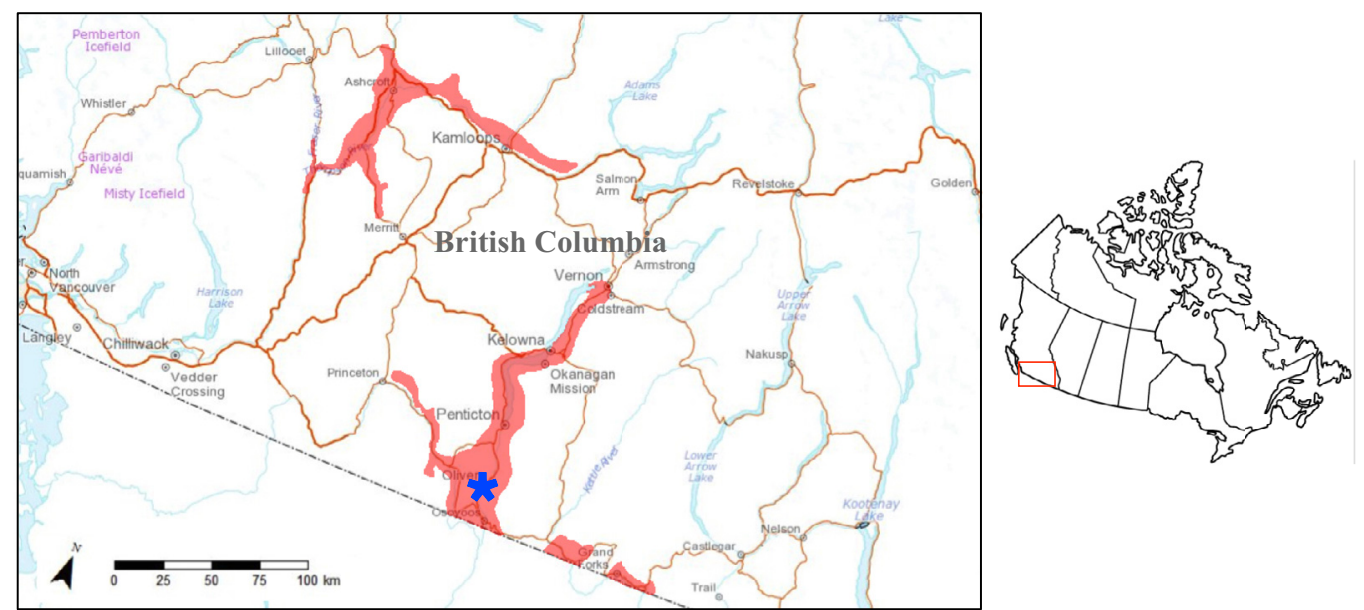

B
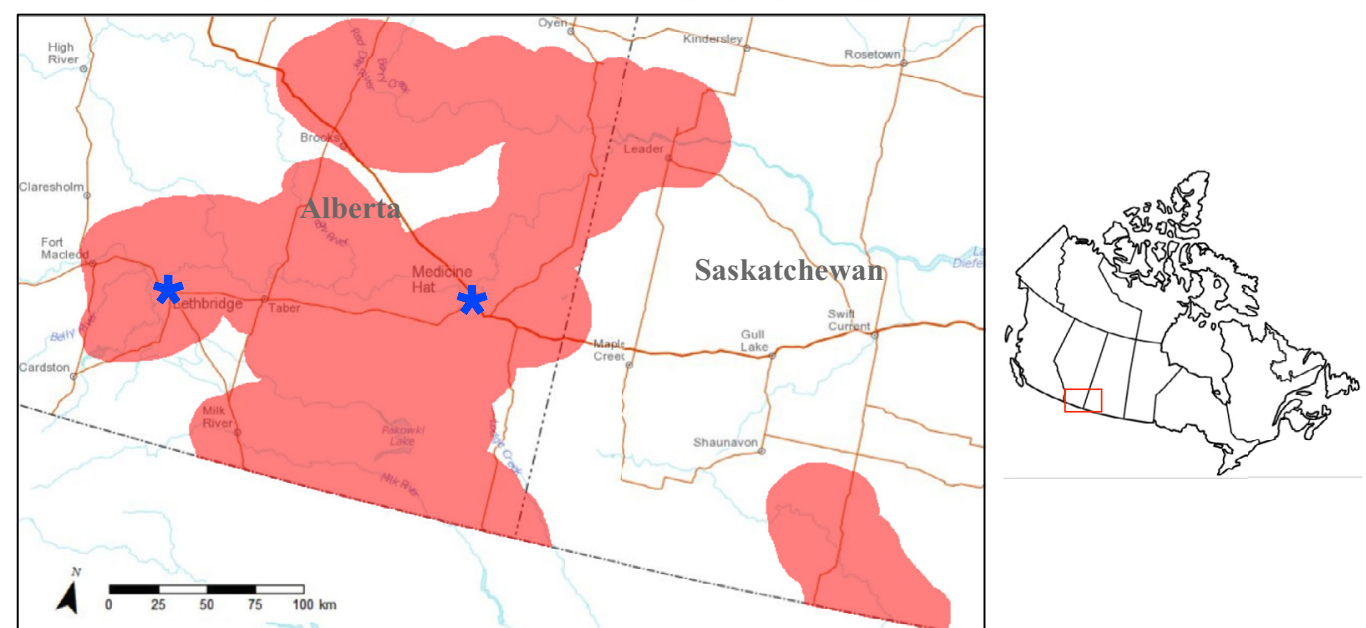

C
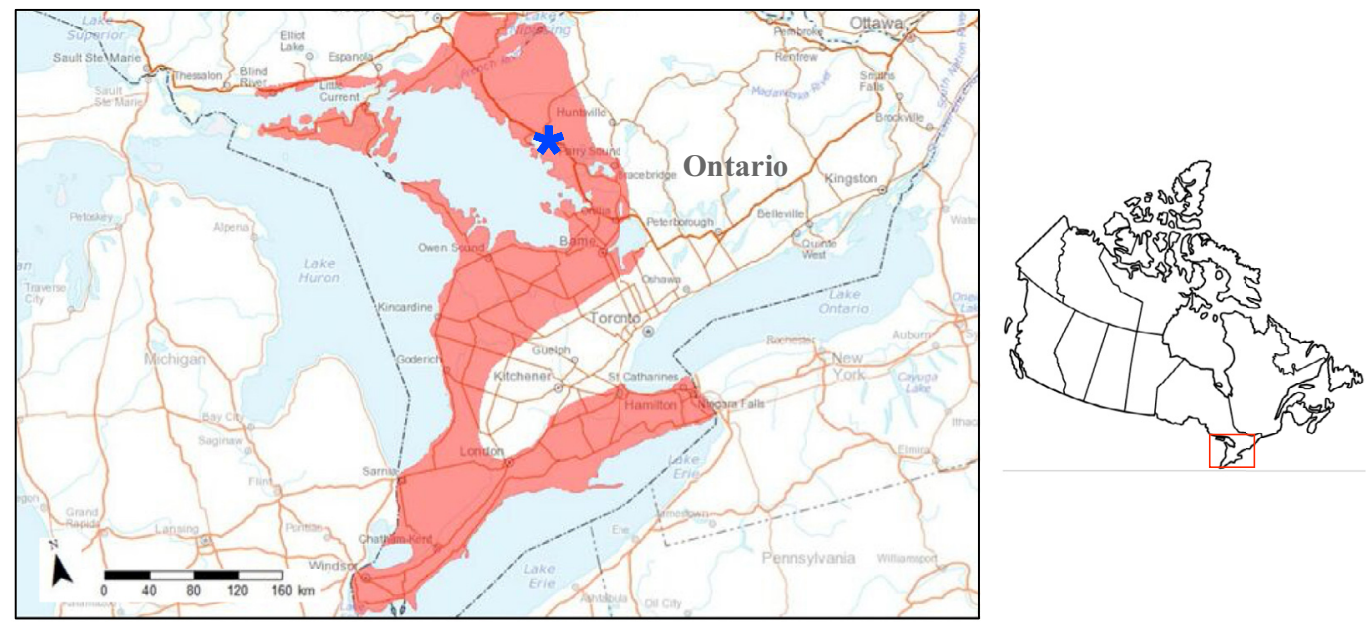

Figure. Endemic distribution of the A, prairie, B, western, and C, eastern massasauga rattlesnakes in Canada. The location of the hospitals that act as regional treatment centers are labeled by a blue star and are represented as A, Oliver in British Columbia, B, Medicine Hat and Lethbridge in Alberta, and C, Parry Sound in Ontario.

There were 99 pit viper envenomations reported in Canada (Table 1) from January 2009 to December 2015 in the HCSAP data with an patient age of $35 \pm 21 \mathrm{y}$ $(2-83)$. The number of envenomations per year was
$14 \pm 6$ (6-21) (Table 2). (Note: the dataset for 2008 only recorded data from a single location, Owen Sound, Ontario, and the above mean does not include data from 2008, so this data was excluded from the multiyear 
Table 1. Patient characteristics of rattlesnake envenomations and antivenom stocking by province and snake species in Canada

\begin{tabular}{|c|c|c|c|c|c|c|c|c|c|}
\hline Geographic region & $\begin{array}{l}\text { Type of } \\
\text { antivenom }\end{array}$ & $\begin{array}{c}\text { Year }(s) \text { request was made to } \\
\text { Health Canada Special } \\
\text { Access Program }\end{array}$ & $\begin{array}{l}\text { Total no. of vials } \\
\text { requested }\end{array}$ & $\begin{array}{l}\text { Total no. of vials } \\
\text { used for treatment }\end{array}$ & $\begin{array}{c}\text { \% of stock } \\
\text { used }\end{array}$ & $\begin{array}{c}\text { No. } \\
\text { patients }\end{array}$ & $\begin{array}{c}\% \\
\text { Male }\end{array}$ & $\begin{array}{c}\text { Age (mean } \pm S D \\
\text { [range]) }\end{array}$ & $\begin{array}{l}\text { Mean no. of vials } \\
\text { for patient } \\
\text { treatment } \pm S D \\
\text { (range) }\end{array}$ \\
\hline British Columbia - Western rattlesnake & CroFab & $2009-2015$ & 1683 & 547 & 33 & 24 & 67 & $37 \pm 20(9-79)$ & $23 \pm 15(4-66)$ \\
\hline Oliver & CroFab & $\begin{array}{c}2009-2010,2012-2013, \\
2015\end{array}$ & 1605 & 541 & 34 & 23 & 65 & $36 \pm 20(9-79)$ & $24 \pm 15(4-66)$ \\
\hline Vancouver & $\mathrm{CroFab}$ & $2009,2011-2013,2015$ & 60 & 6 & 10 & 1 & 100 & 61.0 & 6.0 \\
\hline Victoria & CroFab & $2009,2012,2014$ & 18 & 0 & 0 & 0 & N/A & N/A & N/A \\
\hline Prairie rattlesnake & Both & $2009-2015$ & 577 & 203 & 35 & 19 & 78 & $34 \pm 20(2-72)$ & $11 \pm 4(3-16)$ \\
\hline Alberta & CroFab & $2009-2010,2012-2015$ & 487 & 179 & 37 & $17^{a}$ & 88 & $26 \pm 20(2-72)$ & $7 \pm 4(3-16)$ \\
\hline Calgary & CroFab & $2010-2015$ & 94 & 64 & 68 & 5 & 80 & $30 \pm 22(2-55)$ & $13 \pm 4(6-16)$ \\
\hline Lethbridge & CroFab & $\begin{array}{c}2009-2010,2012-2013, \\
2015\end{array}$ & 149 & 47 & 32 & 5 & 80 & $29 \pm 18(8-60)$ & $9 \pm 5(3-16)$ \\
\hline Medicine Hat & CroFab & $\begin{array}{c}2009-2010,2012 \\
2014-2015\end{array}$ & 224 & 68 & 30 & 6 & 100 & $44 \pm 18(14-72)$ & $11 \pm 4(4-16)$ \\
\hline Hanna & CroFab & 2012,2015 & 20 & 0 & 0 & 0 & N/A & N/A & N/A \\
\hline Saskatchewan & Both & $\begin{array}{c}2009,2011-2012,2015 \pm \\
2016\end{array}$ & 90 & 24 & 27 & 2 & 0 & $26 \pm 12(14-37)$ & $12 \pm 0(12-12)$ \\
\hline Swift Current & CroFab & $2009,2011-2012,2015$ & 66 & 24 & 36 & 2 & 0 & $26 \pm 12(14-37)$ & $12 \pm 0(12-12)$ \\
\hline Royal Saskatchewan Museum ${ }^{b}$ & Antivipmyn & $2015-2016$ & 24 & 0 & 0 & 0 & N/A & N/A & N/A \\
\hline Ontario - Massasauga rattlesnake & Both & $2008-2016$ & 1005 & 719 & 72 & 56 & 54 & $35 \pm 21(2-83)$ & $\begin{array}{r}15 \pm 8(4-38)^{c} \\
16 \pm 9(6-42)\end{array}$ \\
\hline Parry Sound & Antivipmyn & $2009-2016$ & 639 & 531 & 83 & 43 & 49 & $36 \pm 21(2-83)$ & $16 \pm 9(6-42)$ \\
\hline Owen Sound & CroFab & $2009-2010$ & 176 & 164 & 93 & 11 & 73 & $34 \pm 21(2-64)$ & $15 \pm 9(6-38)$ \\
\hline Rogue Valley & CroFab & 2009 & 36 & 24 & 67 & 2 & 50 & $22 \pm 4(18-25)$ & $12 \pm 0(12-12)$ \\
\hline Indian River Reptile Zoo ${ }^{b}$ & Antivipmyn & 2008,2014 & 75 & 0 & 0 & 0 & N/A & N/A & N/A \\
\hline Toronto $\mathrm{Zoo}^{b}$ & Antivipmyn & 2010,2015 & 45 & 0 & 0 & 0 & N/A & N/A & N/A \\
\hline Midland & CroFab & 2009 & 4 & 0 & 0 & 0 & N/A & N/A & N/A \\
\hline Sudbury & $\mathrm{CroFab}$ & 2009 & 18 & 0 & 0 & 0 & N/A & N/A & N/A \\
\hline Toronto Children's Hospital & CroFab & 2009 & 12 & 0 & 0 & 0 & N/A & N/A & N/A \\
\hline Peterborough & CroFab & 2009 & 12 & 0 & 0 & 0 & N/A & N/A & N/A \\
\hline
\end{tabular}

N/A, not applicable.

${ }^{a}$ The treatment location for one of the Alberta patients could not be identified.

${ }^{b}$ Not a healthcare facility.

${ }^{c}$ This represents Crofab and Antivypmin data, respectively. 
Table 2. Yearly distribution of rattlesnake envenomation patients by province and snake species in Canada

\begin{tabular}{|c|c|c|c|c|c|}
\hline Location & Year & $\begin{array}{c}\text { No. of } \\
\text { patients }\end{array}$ & $\begin{array}{c}\text { Percent } \\
\text { males }\end{array}$ & $\begin{array}{c}\text { Age }(\text { mean } \pm S D \\
\text { [range] })\end{array}$ & $\begin{array}{c}\text { No. of vials used for } \\
\text { treatment (mean } \pm S D \\
{[\text { range] })^{a}}\end{array}$ \\
\hline \multicolumn{6}{|c|}{ British Columbia - Western rattlesnake } \\
\hline \multirow[t]{6}{*}{ Oliver } & 2010 & 5 & 40 & $31 \pm 14(11-51)$ & $18 \pm 7(8-24)$ \\
\hline & 2011 & 2 & 50 & $19 \pm 10(9-29)$ & $29 \pm 16(13-44)$ \\
\hline & 2012 & 5 & 80 & $40 \pm 18(8-56)$ & $21 \pm 13(4-44)$ \\
\hline & 2013 & 5 & 80 & $33 \pm 20(14-70)$ & $29 \pm 10(18-44)$ \\
\hline & 2014 & 3 & 33 & $66 \pm 10(55-79)$ & $15 \pm 8(4-24)$ \\
\hline & 2015 & 3 & 100 & $26 \pm 7(18-35)$ & $34 \pm 24(8-66)$ \\
\hline Vancouver & 2013 & 1 & 100 & 61 & 6 \\
\hline \multicolumn{6}{|c|}{ Prairie rattlesnake } \\
\hline \multicolumn{6}{|l|}{ Alberta } \\
\hline \multirow[t]{4}{*}{ Calgary } & 2011 & 1 & 100 & 55 & 6 \\
\hline & 2012 & 1 & 100 & 35 & 12 \\
\hline & 2013 & 1 & 100 & 50 & 16 \\
\hline & 2015 & 5 & 50 & $30 \pm 21(2-55)$ & $13 \pm 6(6-16)$ \\
\hline \multirow[t]{4}{*}{ Lethbridge } & 2009 & 1 & 50 & 56 & 4 \\
\hline & 2010 & 2 & 100 & $13 \pm 5(8-18)$ & $5 \pm 2(3-6)$ \\
\hline & 2013 & 1 & 100 & 60 & 16 \\
\hline & 2015 & 1 & 0 & 33 & 14 \\
\hline \multirow[t]{5}{*}{ Medicine Hat } & 2009 & 1 & 100 & 32 & 12 \\
\hline & 2010 & 1 & 100 & 72 & 12 \\
\hline & 2011 & 1 & 100 & 14 & 4 \\
\hline & 2012 & 2 & 100 & $46 \pm 6(40-52)$ & $12 \pm 0(12-12)$ \\
\hline & 2015 & 1 & 100 & 55 & 16 \\
\hline \multicolumn{6}{|l|}{ Saskatchewan } \\
\hline \multirow[t]{2}{*}{ Swift Current } & 2011 & 1 & 0 & 14 & 12 \\
\hline & 2012 & 1 & 0 & 37 & 12 \\
\hline \multicolumn{6}{|c|}{ Ontario - Massasauga rattlesnake } \\
\hline \multirow[t]{3}{*}{ Owen Sound } & 2008 & 3 & 100 & $30 \pm 25(2-63)$ & $13 \pm 7(4-12)$ \\
\hline & 2009 & 7 & 67 & $33 \pm 18(9-46)$ & $13 \pm 4(6-18)$ \\
\hline & 2010 & 1 & 100 & 59 & 38 \\
\hline \multirow[t]{7}{*}{ Parry Sound } & 2009 & 2 & 50 & $33 \pm 4(29-36)$ & $11 \pm 1(10-12)$ \\
\hline & 2010 & 4 & 75 & $42 \pm 16(18-57)$ & $15 \pm 3(12-18)$ \\
\hline & 2011 & 3 & 33 & $52 \pm 6(46-61)$ & $14 \pm 8(6-22)$ \\
\hline & 2012 & 9 & 62 & $39 \pm 22(9-83)$ & $12 \pm 4(6-18)$ \\
\hline & 2013 & 11 & 36 & $31 \pm 21(12-75)$ & $20 \pm 12(6-40)$ \\
\hline & 2014 & 3 & 0 & $38 \pm 16(16-51)$ & $15 \pm 4(12-20)$ \\
\hline & 2015 & 11 & 55 & $31 \pm 24(2-65)$ & $15 \pm 9(6-36)$ \\
\hline Rogue Valley & 2009 & 2 & 50 & $22 \pm 4(18-25)$ & $12 \pm 0(12-12)$ \\
\hline
\end{tabular}

${ }^{a}$ All sites used CroFab except for Parry Sound, which used Antivipym.

analysis.) This equates to an annual incidence of 4 envenomations per 1,000,000 inhabitants, where the denominator is the combined population of each of the cities where an envenomation was treated. ${ }^{16}$ By snake species, the number of envenomations per year was reported for the western rattlesnake as $4 \pm 1(2-6)$, the prairie rattlesnake as $3 \pm 2(2-7)$, and the eastern massasauga rattlesnake as $7 \pm 4$ (3-11). Two sites, Oliver, British Columbia and Parry Sound, Ontario, showed consistent patient presentations to healthcare facilities for snakebites on a yearly basis. Male patients accounted for $62 \%$ of envenomation victims. The number of vials used for patient treatment was $16 \pm 11(3-66)$, which broke down to $17 \pm 12(3-66)$ and $16 \pm 9(6-42)$ for CroFab and Antivipmyn, respectively.

British Columbia, Alberta, and Saskatchewan have exclusively used CroFab for patient treatment, while Ontario has experience with CroFab and Antivipmyn. Ontario transitioned to exclusively using Antivipmyn in 2010. The Owen Sound healthcare facility and Indian 
River Reptile Zoo in Ontario also obtained antivenom through the HCSAP before 2009. All facilities making requests for antivenom were healthcare facilities except for a museum in Saskatchewan (hosting a reptile exhibit) and 2 zoos in Ontario. The cities where most patients received treatment included (where percentages are shown on a provincial basis): Oliver (96\%) in British Columbia; Calgary (29\%), Lethbridge (29\%), and Medicine Hat (35\%) in Alberta; Swift Current (100\%) in Saskatchewan; and Owen Sound (20\%) and Parry Sound (77\%) in Ontario. Each of these cities contained community hospitals, except for Calgary, which has multiple academic centers. All hospitals in Canada have access via telecommunication to provincially or regionally administered poison control centers; however, only Calgary has a poison control center in its city.

The eastern massasauga rattlesnake was responsible for $57 \%$ of venomous snakebites in Canada, ahead of the western rattlesnake and prairie rattlesnake, which represented $24 \%$ and $19 \%$, respectively. The number of vials for patient treatment as a function of species was reported for the western rattlesnakes as $23 \pm 15$ (4-66), the prairie rattlesnakes as $11 \pm 4(3-16)$, and the eastern massasauga rattlesnakes as $15 \pm 8(4-38)$ for $\mathrm{CroFab}$ and $16 \pm 9$ (6-42) for Antivipmyn.

A normal distribution was observed for the monthly pit viper envenomations and found the majority of envenomations occurred in July.

Antivenom stock usage varied across the country and was reported for British Columbia as $33 \%$, Alberta as $37 \%$, Saskatchewan as $27 \%$, and Ontario as $72 \%$ (Table 1). Stock utilization improved compared with the provincial means at the regional treatment centers of Oliver (34\%), Swift Current (36\%), and Parry Sound (83\%). The costs incurred secondary to forfeited stock between January 2009 and December 2015 were $\$ 1,280,000$ USD in British Columbia (CroFab 512 vials), \$255,000 USD in Alberta (CroFab102 vials), \$60,000 USD in Saskatchewan (CroFab 24 and Antivipmyn 0 vials), and $\$ 0$ in Ontario (CroFab -12 and Antivipmyn - 77 vials; the negative number represented unused, unexpired antivenom).

\section{Discussion}

This is the first known literature to report on the epidemiology of envenomations by pit viper species endemic to Canada. The age of an envenomation patient was $35 \pm$ 21 years $(2-83)$, and $62 \%$ were male. This is similar to the literature ${ }^{5,17}$ for pit viper species in the United States. This study did not evaluate the types of activities the patients were engaged in when bitten, the anatomic locations of bites, the severity of the envenomations, the level of treatment required, or if any fatalities occurred. Potentially this information could be ascertained with a future case series investigation.

In Ontario, the Ontario Massasauga Rattlesnake Antivenom Depot has established regional guidelines for the treatment of eastern massasauga rattlesnake envenomations with Antivipmyn. ${ }^{18}$ Before 2010, CroFab was used in Ontario according to the manufacturer's guidelines. The poison control centers for British Columbia and Alberta (the Poison and Drug Information System in Alberta also services Saskatchewan) use CroFab as their antivenom for the treatment of pit viper snakebites and use the manufacturer's recommended treatment guidelines. ${ }^{19}$

The number of antivenom vials for patient treatment after envenomation by a pit viper species found in Canada varied greatly. It is difficult to compare this with data from the United States as it is not possible to quantify the severity of the envenomation from the HCSAP data. A review of the FabAV literature by Lavonas et al identified 12 patients with severe North American pit viper envenomations and calculated the number of vials to achieve initial control as $9 \pm 4(4-18) .{ }^{20}$ The HCSAP data showed the number of vials for patients treated with CroFab was $23 \pm 15$ (4-66) for the western rattlesnake, $11 \pm 4(3-16)$ for the prairie rattlesnake, and $15 \pm 8$ (4-38) for the eastern massasauga rattlesnake. These means included both the initial control and maintenance treatment doses. If 6 vials for the manufacturer-recommended maintenance treatment are subtracted, this would indicate that the envenomations from the western, prairie, and eastern massasauga rattlesnakes could be classified as moderate to severe when taking the standard deviations into account. By comparison, the number of vials of Antivipmyn for eastern massasauga bites was $16 \pm 9$ (6-42), and this included both the initial control and maintenance doses. Surprisingly, this was not double the CroFab mean because the relative potency of Antivipmyn is half that of CroFab. ${ }^{21-23}$ Bush et al reported the number of Antivipmyn vials as $27 \pm 7$ (22-46) for Crotalinae bites in the southern United States with a snakebite severity score of $4 \pm 2(1-11)$, which equates to a moderate envenomation. ${ }^{21}$ Given these findings and the results of this study, it implies that the bites by the eastern massasauga rattlesnake of Canada resulted in mild to moderate envenomations. However, characterizing the severity of a snakebite by the amount of antivenom used for treatment suffers from several potential errors (provider adherence to treatment guidelines, difficulty achieving initial control, among others) and is not a validated means for assigning the severity of envenomation. Unfortunately, the HCSAP data did not allow for the calculation of a snakebite severity score, ${ }^{24,25}$ as clinical and laboratory information was not captured in the 
dataset. Ultimately, the classification of envenomation severity based on treatment should only serve as a rough guide and additional evaluation of Canadian envenomations is necessary to better characterize the severity of these encounters.

British Columbia, Alberta, and Saskatchewan incurred substantial costs associated with forfeited antivenom stock, while Ontario did not forfeit any stock. Gaining a better estimate of regional need based upon prior trends could reduce forfeited stock in British Columbia and Saskatchewan as the clear majority of patients and antivenom stock were in Oliver and Swift Current, respectively. By comparison, creating a rapid access central repository may be a means to address forfeited stock seen in Alberta as Calgary, Medicine Hat, and Lethbridge as all are within 2 to $3 \mathrm{~h}$ by road of one another. Such an approach could reduce the forfeited stock for each of these 3 sites. In addition to forfeited stock, it is known that bites that lead to minor symptoms typically do not require antivenom treatment. ${ }^{3}$ As such, central to this antivenom stock discussion is developing a better characterization of the severity of patient presentations and when there is a need for antivenom treatment after a snakebite by species native to Canada. ${ }^{26-28}$

Emergence from winter hibernacula and the end of hibernation begins in late March or early April for the western and prairie rattlesnakes and in May for the eastern massasauga rattlesnake. This active period extends into early October for all species. ${ }^{10-12}$ The temporal distribution of bites seen in this study reflects well the active period of these snake species. There was a single case that occurred in January; however, there was a concern with the legibility of the handwritten information contained in this special access request form A. It is possible that this patient had a pit viper species as a pet and the envenomation occurred in January or they sustained the envenomation in a location outside of Canada and were repatriated back to Canada.

The yearly variation in envenomation frequency (Table 2) seen across the country is likely related to local fluctuations in outdoor activity, tourist activity, and changes in the snake populations secondary to predation, poaching, and/or animal destruction. The American Association of Poison Control Centers reported 4046 pit viper envenomations in 2012. Of these, there was 1 fatality and $57 \%$ of bites produced a moderate or major outcome, as defined by the American Association of Poison Control Centers. ${ }^{27}$ Given the large discrepancy in the size of the pit viper populations and the expansive geographic area where these snakes are found in the United States, it would be expected that the number of envenomations in Canada would be a fraction of those reported for the United States, as seen in this study. It is unlikely that there is underreporting of envenomations that require treatment at a healthcare facility in Canada since antivenom must be obtained through the HCSAP. However, snakebites are not reportable at the provincial or federal level as these species are not responsible for the transmission of rabies. As such, there may be some number of snakebites-dry bites, mild envenomations-that do not require treatment with antivenom and are not captured in the HCSAP data.

The regional treatment centers of Oliver, Lethbridge, Medicine Hat, and Parry Sound likely represent locations that are near major summer feeding grounds for their respective pit viper species. However, this explanation is not relevant to Calgary because it is not within the endemic distribution of the prairie rattlesnake, and it is not clear why this site is encountering frequent envenomation patients. According to the HCSAP data, Calgary is not acting as a referral site for patients in southern Alberta. It is possible that warmer seasonal weather ${ }^{28}$ is leading to a more northerly distribution of the prairie rattlesnake, but this is yet to be confirmed by herpatology data. Alternatively, Calgary may be acting as a referral center for pit viper envenomation patients repatriated from outside Canada to the province. The hospitals in Oliver and Parry Sound treated $67 \%$ of all envenomation patients encountered in Canada. It is not clear if these facilities are acting as the referral centers for their respective regions or if patients are directly presenting to these centers after sustaining a snake bite. Given the size of the endemic areas for the western and eastern massasauga rattlesnakes, it is likely that the former is true.

\section{Limitations}

The resources used to create the endemic maps were from 1993 to 2015. There were data from 2012 and 2015 for the eastern massasauga and prairie rattlesnakes, respectively, but for the western rattlesnake, the newest data were from 2004. It is conceivable that some inaccuracy in the geographic maps exists given the age of the available data.

One researcher (JK) created the database but was not blinded to the study objectives. A limited bias effect was expected as the HCSAP documentation was translated with minimal or no interpretation of the information. Because Health Canada started to act as the conduit for antivenom in 2009, it is unlikely that all envenomations before 2009 were captured in this dataset. After 2009, it is assumed that all envenomations in Canada that required antivenom administration were captured in the HCSAP documentation. However, it is possible that some number of Canadian envenomations that did not require medical attention or did not receive antivenom, 
among other possibilities, were not captured in the HCSAP documentation. It is not possible to estimate the size of any uncaptured envenomations. There may be an overrepresentation of moderate or severe envenomations in the HCSAP data, as minor envenomations do not generally require the use of antivenom and would not have warranted the creation of a Health Canada request form. It is also possible that patients with minor envenomation symptoms did not present to a healthcare facility. Health Canada tracked antivenom requests with paper records, and it is conceivable that human error could have led to misplacement or lost documents.

The assumptions used to determine the snake species responsible for the HCSAP data appear reasonable. However, all of the HCSAP cases are more accurately characterized as suspected envenomations by endemic pit viper species in Canada as the dataset did not provide any definitive evidence of what animal caused the bite.

The model used to estimate the potential costs associated with expired antivenom should be viewed as a simplified representation as it does not consider antivenom forfeited to other causes beyond expiration, wastage, or antivenom given to another jurisdiction before its expiration.

\section{Conclusions}

This is the first known Canadian-based literature to report on the frequency of envenomations by venomous snakes endemic to the country and on the geographic distributions of these encounters. The absolute number of annual envenomations is small and the 3 Crotalinae species are limited to relatively narrow geographic areas in British Columbia, Alberta, Saskatchewan, and Ontario. Simple patient demographics were also presented and showed that younger males were dominant in this group. The utilization of antivenom in the treatment of these patients revealed that regions where the western and prairie rattlesnake reside forfeited a tangible amount of antivenom from 2009 to 2015. Organizations responsible for maintaining antivenom supplies on a provincial or regional level could use these data to guide antivenom stocking. Future studies should focus on either retrospective or prospective investigations to quantify the severity of envenomations on a species level, and clinical trials could be used to determine the contribution of antivenom treatment to clinical outcomes.

Acknowledgments: The authors thank Neil McDonald and Ryan Chuang for their review of the manuscript and provision of critical feedback.

Author Contributions: Conceived the study and obtained the data for the study (GC); conducted the statistical analysis (GC); created the figures and tables (JK); drafted the manuscript (GC); contributed substantially to its revision (JK); assumes responsibility for the article as a whole (GC).

Financial/Material Support: None.

Disclosures: None.

\section{References}

1. Government of Ontario. Timber rattlesnake. Available at: https://www.ontario.ca/page/timber-rattlesnake. Accessed January 22, 2018.

2. Gold BS, Dart RC, Barish RA. Bites of venomous snakes. N Engl J Med. 2002;347(5):347-56.

3. Gold BS, Barish RA, Dart RC. North American snake envenomation: diagnosis, treatment, and management. Emerg Med Clinics N Am. 2004;22(2):423-43.

4. Cardwell MD. Recognizing dangerous snakes in the United States and Canada: a novel 3-step identification method. Wilderness Environ Med. 2011;22(4):304-8.

5. Kanaan NC, Ray J, Stewart M, Russell KW, Fuller M, Bush SP, et al. Wilderness Medical Society practice guidelines for the treatment of pit viper envenomations in the United States and Canada. Wilderness Environ Med. 2015;26(4):472-87.

6. Blood DA. Wildlife in British Columbia at risk: western rattlesnake. Victoria, British Columbia: Province of British Columbia Ministry of Environment, Lands, and Parks; 1993:1-6.

7. Sarell M. Western Rattlesnake-Crotalus oreganus. Accounts and Measures for Managing Identified Wildlife - Accounts V. Victoria, Canada: Ministry of Environment \& Climate Change Strategy; 2004:2.

8. Alberta Parks. Writing-on-Stone Provincial Park rattlesnakes; 2007. Available at: https://open.alberta.ca/dataset/ 9f6870ef-8e2c-49db-9e5a-3f5f26bef762/resource/ 16103925-4f52-4880-853d-cad6ce7880c8/download/2007wos-rattlesnakes.pdf. Accessed January 22, 2018.

9. Kissner KJ. Status of the Prairie Rattlesnake (Crotalus viridis) in Alberta: Update 2012. Alberta Wildlife Status Report No. 6. Edmonton, Canada: Alberta Environment and Sustainable Resource Development; 2012. 3,6,12.

10. Brooks R. Assessment and Status Report on the Western Rattlesnake Crotalus Oreganus in Canada. Ottawa, Canada: Committee on the Status of Endangered Wildlife in Canada; 2004:3-5. 9; https://www.sararegistry.gc.ca/ virtual_sara/files/cosewic/sr_western_rattlesnake_e.pdf.

11. Choquette J, Martison A. Assessment and Status Report on the Prairie Rattlesnake Crotalus Viridis in Canada. Ottawa, Canada: Committee on the Status of Endangered Wildlife in Canada; 2015:11-15.

12. Choquette J, Preney T. Assessment and Status Report on the Massasauga Sistrurus Catenatus in Canada. Ottawa, Canada: Committee on the Status of Endangered Wildlife in Canada; 2012:16-22.

13. World Health Organization. Venomous snakes distribution and species risk categories. Available at: http://apps.who. int/bloodproducts/snakeantivenoms/database/default.htm. Accessed January 22, 2018. 
14. NatureServe Explorer: An online encyclopedia of life [web application]. Version 7.1. Arlington, VA: NatureServe. Available at: http://explorer.natureserve.org. Accessed January $22,2018$.

15. Natural Resource Canada. The Atlas of Canada-Toporama program. Available at: http://atlas.gc.ca/top orama/en/index.html. Accessed January 22, 2018.

16. Statistics Canada. Population and dwelling counts, for Canada, provinces and territories, and census subdivisions (municipalities), 2016 and 2011 censuses-100\% data. Available at: http://www12.statcan.gc.ca/census-recensement/2016/dp-pd/h lt-fst/pd-pl/Table.cfm?Lang=Eng \&T=302\&SR=1\&S=86\&O= $A \& R P P=9999 \& P R=48$. Accessed January 22, 2018.

17. Morgan BW, Lee C, Damiano L, Whitlow K, Geller R. Reptile envenomation 20-year mortality as reported by US medical examiners. South Med J. 2004;97(7):642-4.

18. Fargher TJ. Antivipmyn Treatment Package. The Ontario Massasauga Rattlesnake Antivenom Depot. Available at: https://www.wpshc.com/index.php/ontario-antivenomdepot-117. Accessed January 22, 2018.

19. Dart RC, Seifert SA, Boyer LV, Clark RF, Hall E, McKinney $\mathrm{P}$, et al. A randomized multicenter trial of crotalinae polyvalent immune Fab (Ovine) antivenom for the treatment for crotaline snakebite in the United States. Arch Intern Med. 2001;161(16):2030-6.

20. Lavonas EJ, Schaeffer TH, Kokko J, Mlynarchek SL, Bogdan GM. Crotaline Fab antivenom appears to be effective in cases of severe North American pit viper envenomation: an integrative review. BMC Emerg Med. 2009;9:13.

21. Bush SP, Ruha AM, Seifert SA, Morgan DL, Lewis BJ, Arnold TC, et al. Comparison of $\mathrm{F}\left(\mathrm{ab}^{\prime}\right) 2$ versus Fab antivenom for pit viper envenomation: a prospective, blinded, multicenter, randomized clinical trial. Clin Toxicol. 2015;53(1):37-45.

22. Boyer LV, Chase PB, Degan JA, Figge G, Buelna-Romero A, Luchetti C, et al. Subacute coagulopathy in a randomized, comparative trial of Fab and F(ab') 2 antivenoms. Toxicon. 2013;74:101-8.

23. Sanchez EE, Galan JA, Perez JC, Rodriguez-Acosta A, Chase PB, Perez JC. The efficacy of two antivenoms against the venom of North American snakes. Toxicon. 2003;41(3):357-65.

24. Dart RC, Huribut KM, Boren J. Validation of a severity score for the assessment of crotalid snakebites. Ann Emerg Med. 1996;27(3):321-6.

25. Yin S, Kokko J, Lavonas E, Mlynarchek S, Bogdan G, Schaeffer T. Factors associated with difficulty achieving initial control with Crotalidae polyvalent immune Fab antivenom in snakebite patients. Acad Emerg Med. 2011;18(1):46-52.

26. Malonea E, King A, Aaron C. A case series of eastern massasauga rattlesnake envenomations. NACCT Abstracts 2016. Clin Toxicol. 2016;54(8):659-811.

27. Mowry JB, Spyker DA, Cantilena LR, Bailey JE, Ford M. Annual report of the American Association of Poison Control Centers' national poison data system (NPDS): 30th annual report. Clin Toxicol. 2013;51(10): 949-1229.

28. Yanez-Arenas C, Peterson AT, Podriguez-Medina K, Barve N. Mapping current and future potential snakebite risk in the new world. Clim Change. 2016;134(4):697-711. 